\title{
O Princípio da Capacidade Contributiva nos Impostos, nas Taxas e nas Contribuições Parafiscais
}

\author{
Ricardo Lodi Ribeiro*
}

\section{RESUMO}

O artigo objetiva analisar as mudanças decorrentes da passagem do Estado Social para o Estado Social e Democrático de Direito na idéia de Justiça Fiscal, à luz do princípio da capacidade contributiva, a fim de examinar a aplicação do princípio aos impostos, às taxas e as contribuições parafiscais.

PALAVRAS-ChAVE: Justiça Comutativa. Justiça Distributiva. Custo-Benefício. Solidariedade de Grupo. Referibilidade. Personificação.

\begin{abstract}
The present article aims to analyse the changes resulting from the passage of Social State to Social and Democratic State of Law in the idea of Fiscal Justice, under the principle of ability to pay, in order to examine the application of principle to taxes, fees and parafiscal contributions.
\end{abstract}

KEYWORDS: Commutative Justice. Distributive Justice. Cost-Benefit Analysis. Group Solidarity. Referibilidade. Embodiment.

\section{1) O Fundamento da Capacidade Contributiva}

O princípio da Capacidade Contributiva busca seu fundamento na idéia de Justiça fiscal, ${ }^{1}$ a partir de uma visão aristotélica de Justiça como Igualdade. ${ }^{2}$ Essa visão no Estado Liberal traduziu-se na Justiça comutativa, baseada no princípio do Custo-Benefício, a partir da teoria do benefício de Adam Smith. O Custo-Benefício determina que cada um paga em razão dos benefícios obtidos. Esse pensamento, associado à entronização da proteção à propriedade e ao indivíduo como valores centrais da sociedade burguesa, partia do pressuposto que o benefício que cada um extraía da atuação estatal, limitada a garantir a Segurança Jurídica dos proprietários, era proporcional a sua riqueza, o que justificava a vinculação da Capacidade Contributiva ao princípio do Custo-Benefício não só em relação às

\footnotetext{
* Professor Adjunto de Direito Financeiro da UERJ. Coordenador da Pós-Graduação em Direito Tributário da FGV-DIREITO-RIO. Doutor em Direito e Economia pela UGF, Mestre em Direito Tributário pela UCAM. Advogado.

1 TIPKE, Klaus. "Princípio da Igualdade e a Idéia de Sistema no Direito Tributário". In: BRANDÃO MACHADO (coord.). Estudos em Homenagem ao Prof. Ruy Barbosa Nogueira. São Paulo: Saraiva, 1984 "Princípio da Igualdade e a Idéia de Sistema no Direito Tributário", p. 517.

${ }^{2}$ Vide em ARISTÓTELES. Ética A Nicômaco. São Paulo: Martin Claret, 2000, p. 108-116, a idéia de justiça como igualdade, que se revela pela: a) justiça comutativa, baseada nas trocas, a partir da relação de igualdade entre o que se dá e o que se recebe; e b) justiça distributiva, que se aplica na repartição das honras e dos bens da comunidade, segundo a noção de que cada um perceba o proveito adequado a seus méritos.
} 
taxas e contribuições de melhoria como hoje se dá, mas inclusive em relação aos impostos, informados pelo princípio da proporcionalidade tributária.

No Estado Social, que precisava custear as prestações sociais positivas destinadas aos trabalhadores, a Capacidade Contributiva passou a ser fundamentada na Justiça distributiva, por meio da Solidariedade Social, a informar o princípio da personificação aplicável impostos, a partir da pesquisa de dados vinculados ao patrimônio e à renda do contribuinte, em todas as suas dimensões, uma vez que, como se demonstrará adiante, todos os fatos geradores dos impostos se reduzem a essas duas manifestações de riqueza. ${ }^{3}$ É a personificação, índice de capacidade contributiva aplicável a partir de dados que revelam a riqueza do contribuinte por meio da patrimonialidade (riqueza estática) ou pessoalidade (riqueza dinâmica), independentemente de qualquer contraprestação estatal. O princípio da personificação se revela como o índice de capacidade contributiva aplicável aos impostos, admitindo a investigação do patrimônio, da renda e dos serviços do contribuinte (art. 145, §1 $\mathrm{CF}$ ), inclusive nos impostos reais por meio da patrimonialidade, não se confundindo com a pessoalidade ou personalização, característica dos impostos pessoais. A confusão que a maior parte da doutrina faz entre a personificação e a pessoalidade tem contribuído para a tendência de reduzir o conteúdo da Capacidade Contributiva à mensuração de dados relativos à riqueza do contribuinte (personificação), e em conseqüência aos impostos, quando na verdade, como manifestação da Justiça tributária, tem amplitude aplicável a todos os tributos. A personificação permite não só a identificação dos critérios mais proximamente relacionados com a pessoa do contribuinte (pessoalidade), como a renda, mas também aqueles ligados ao seu patrimônio, o que ocorre, predominantemente, nos impostos reais. Nestes o legislador não deixa de mensurar a manifestação de riqueza do contribuinte. No entanto, esta se revela por uma conduta que guarda uma relação mais estreita com o seu patrimônio.

Mas em ambos os casos, o que se quantifica não é outra coisa que não a riqueza do contribuinte revelada pelo fato gerador do tributo (personificação). Com agigantamento das despesas de previdência e saúde foram criadas no Estado Social as contribuições parafiscais, com base na mesma lógica da Solidariedade e da personificação.

Com o advento do Estado Social e Democrático de Direito, há, na fase de legitimação do ordenamento jurídico, uma ponderação entre a Liberdade do Estado Liberal e a Solidariedade do Estado Social. Nesse contexto, a Capacidade Contributiva une os elementos da Justiça comutativa com os da Justiça distributiva, viabilizando o surgimento da

\footnotetext{
${ }^{3}$ PEREZ DE AYALA, Jose Luis. Derecho Tributario I. Madrid: Editorial de Derecho Financiero, 1968, p. 89.
} 
Solidariedade de Grupo ou Custo-Benefício coletivo, em relação às contribuições parafiscais, que deixam de ser informadas pela Solidariedade Social em sentido genérico, que fica restrita aos impostos e aos empréstimos compulsórios que utilizem o fato gerador desses. A Solidariedade de Grupo é revelada a partir da destinação do tributo a uma atividade estatal que guarda referência, não com a pessoa do contribuinte, mas com o grupo econômico ou social que ele participa. Note-se que neste caso, a referibilidade de grupo se apresenta, ao contrário do que ocorre nas taxas e contribuições de melhoria, na destinação legal do produto da arrecadação, necessariamente relacionado ao grupo, e não no fato gerador, que poderá ser uma atuação do contribuinte desvinculada a qualquer atividade estatal a ele relativa. Por isso as contribuições parafiscais são tributos necessariamente afetados, embora possam ser vinculados ou não-vinculados, de acordo com o seu fato gerador de taxa ou imposto. ${ }^{4}$

Assim, no Estado Social e Democrático de Direito, a Capacidade Contributiva incorpora os elementos da Justiça comutativa, caros ao Estado Liberal, a partir do princípio do Custo-Benefício, aplicável às taxas e às contribuições de melhoria, por meio da referibilidade individual. Por outro lado, e esse é o seu traço mais característico, mantém laços significativos com a Justiça distributiva do Estado Social, a partir da idéia de Solidariedade Social, fundamento dos impostos e dos empréstimos compulsórios, ${ }^{5}$ com base na personificação. Porém, funde os elementos da Justiça comutativa e da Justiça distributiva, por meio da Solidariedade de Grupo, baseada numa relação de custo-benefício coletivo, aplicável a todo o grupo e não ao indivíduo, característica encontrada nas contribuições parafiscais através da referibilidade de grupo. Contudo, é importante lembrar que no nosso direito constitucional tributário positivo, em face da pouca percepção do legislador em relação à mudança de paradigma do Estado Social para o Estado Social e Democrático de Direito, existem as falsas contribuições, que nada mais são do que impostos com destinação específica, ${ }^{6}$ uma vez que os grupos passaram a ser tão ampliados que acabaram por se diluir na sociedade genericamente considerada, como as incidentes sobre a receita e lucro das empresas, sobre (art. 195, I, $b$ e $c, \mathrm{CF}$ ) e folha de salários (salário educação, art. 212, CF),

\footnotetext{
${ }^{4}$ Vide: RIBEIRO, Ricardo Lodi. "As Contribuições Parafiscais e a Validação Constitucional das Espécies Tributárias". In: RDDT $\mathrm{n}^{\circ} 174,2010$, p. 110-129, onde defendemos, a partir de uma perspectiva quinquipartite, que os tributos são impostos, taxas, contribuições de melhoria, contribuições parafiscais e empréstimos compulsórios, caracterizando-se os três primeiros por fatos geradores próprios e os dois últimos pela destinação legal do produto da arrecadação, uma vez que estes se utilizam dos fatos geradores de impostos e taxas.

${ }^{5}$ Os empréstimos compulsórios quase sempre adotam o fato gerador dos impostos e, por isso, seguem a técnica de capacidade contributiva e eles relativa. Porém, excepcionalmente, seu fato gerador se configura como o da taxa, casos em que passarão a ser regulados pelo princípio do Custo-Benefício.

${ }^{6}$ TORRES, Ricardo Lobo. Tratado de Direito Constitucional Financeiro e Tributário, Vol. IV - Os Tributos na Constituição. Rio de Janeiro: Renovar, 2007, p. 557. RIBEIRO, Ricardo Lodi. "As Contribuições Parafiscais e a Validação Constitucional das Espécies Tributárias, p. 120.
} 
bem como sobre a receita de concursos de prognósticos (art. 195, III, CF) e importação (art. 195, IV , CF), cuja disciplina, em relação à Capacidade Contributiva, não é outra que não a dos impostos.

A superação do modelo baseado exclusivamente nos impostos é decorrência da introdução do Estado Social no século XX, quando, no que se refere a instituição de tributos, a preocupação com as causas da tributação (fato gerador) não é mais exclusiva, pois surge a questão também quanto às finalidades. ${ }^{7}$ Esse novo modelo é também mais adequado ao Estado Social e Democrático de Direito e à sociedade de risco, em que o passado não mais oferece critérios para a solução dos problemas do presente, aumentando a demanda por mecanismos tributários que, abandonando o clássico modelo baseado exclusivamente no fato gerador e na capacidade contributiva, como manifestação de riqueza já conhecida, sejam capazes de prevenir e atenuar os riscos futuros. Por outro lado, com a repartição de bads e goods pelos cidadãos, os benefícios sociais que determinado grupo aufere com a atuação estatal, bem como a prevenção dos riscos por ele causados, não devem ser atribuídos ao conjunto da sociedade, que suporta o pagamento dos impostos. Mas ao próprio grupo que demanda intervenção governamental. ${ }^{8}$ Com isso, na sociedade de risco começamos a assistir ao início do longo processo de superação do Estado dos Impostos para a consagração do Estado das Taxas, em que as despesas públicas cujos beneficiários possam ser identificados passam a ser custeadas por tributos (sejam taxas ou contribuições) que se caracterizam pela atividade estatal por eles financiada, ficando os impostos para as despesas gerais do Estado. ${ }^{9}$

Evidentemente quando se fala em Estado das Taxas não se está pretendendo a volta do princípio do custo-benefício de matiz exclusivamente individual que caracterizou a Justiça Comutativa do Estado Liberal. Mas sim evitar que os excessos que foram praticados no auge do Estado Social onde, a partir de uma ótima distorcida de Justiça Distributiva, as despesas estatais de indivíduos ou grupos, não necessariamente os mais pobres, mas os mais articulados na captação de recursos estatais, serviu para justificar a tributação baseada exclusivamente na finalidade social de impostos e contribuições que não guardam qualquer relação com seus contribuintes. Com o advento do Estado Social e Democrático de Direito, onde a Justiça Distributiva entra em ponderação com a Justiça Comutativa na fase de legitimação do ordenamento jurídico, o princípio do custo-benefício ganha uma dimensão coletiva e democrática, baseada na solidariedade de grupo, determinando que as despesas relacionadas a

7 GRECO, Marco Aurélio. Contribuições (uma figura "sui generis"), p. 136.

8 RIBEIRO, Ricardo Lodi. A Segurança Jurídica do Contribuinte, p. 58-59.

9 TORRES, Ricardo Lobo. Tratado de Direito Constitucional Financeiro e Tributário - Vol. II - Valores e Princípios Constitucionais Tributários. Rio de Janeiro: Renovar, 2005 , p. 375 . 
um segmento específico de contribuintes seja financiada pelos seus próprios integrantes, e não suportada pela sociedade em geral por meio dos impostos. Com isso, o plano de saúde da classe média, por exemplo, tem sua fiscalização financiada pelos próprios integrantes do setor e seus consumidores, não onerado o orçamento público da saúde que poderá ser destinado a sociedade como um todo, em especial aos mais necessitados.

Deste modo, a fundamentação da Capacidade Contributiva nos diferentes tributos apresenta-se esquematizada da seguinte forma:

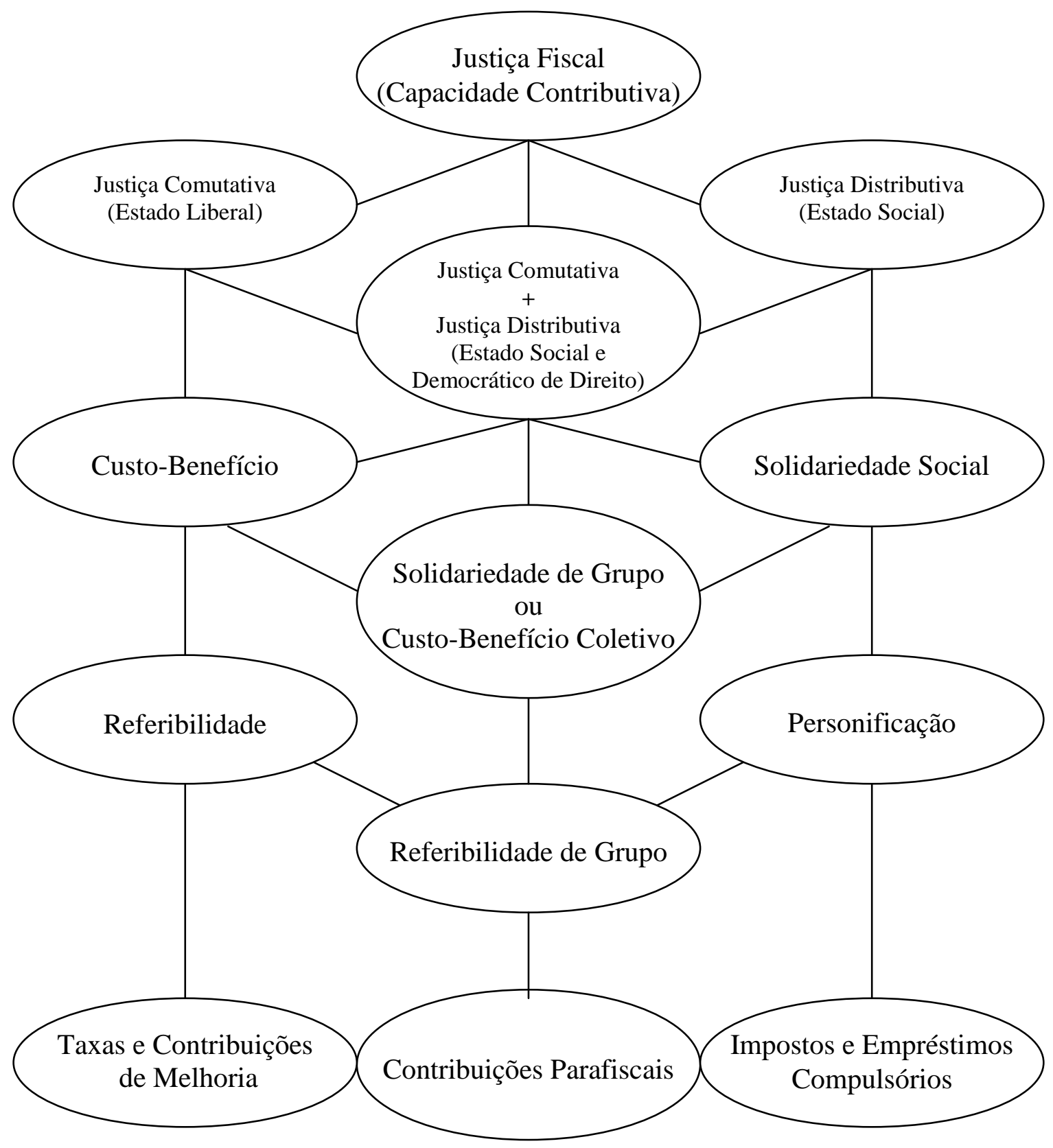




\section{2) O Conteúdo do Princípio da Capacidade Contributiva}

Como se viu, o princípio da Capacidade Contributiva encontra seu fundamento na Justiça Fiscal e na Igualdade, ${ }^{10}$ na medida em que todos devem contribuir para as despesas públicas, em razão de suas possibilidades econômicas, ainda que não sejam diretamente beneficiários dessas despesas. Assim, de acordo com esta diretriz, legítimas são as distinções que se baseiem na diferença entre as riquezas que vários contribuintes manifestam. ${ }^{11}$

Nessa perspectiva igualitária, há que se inquirir em relação ao que as coisas são iguais e, a partir daí, averiguar se as distinções encontradas justificam, de fato, a atribuição de um tratamento diferenciado pelo legislador tributário. As distinções que devem ser levadas em consideração pela lei são as que se baseiam numa diferente manifestação de riqueza, salvo se presente outro fundamento a ser ponderado com a Capacidade Contributiva.

Por outro lado, sob a perspectiva da Solidariedade, sendo uma das tarefas do Estado Social e Democrático de Direito a garantia da dignidade da pessoa humana - o que está sempre a exigir prestações estatais positivas - é necessário angariar recursos daqueles cuja sobrevivência digna não depende das prestações estatais para, desta forma, socorrer os reclames elementares da grande massa que, embora não tenha recursos para contribuir, necessita das prestações estatais. Nesse sentido, o princípio da Capacidade Contributiva, como instrumento da Justiça distributiva, promove a redistribuição de rendas.

Segundo Ricardo Lobo Torres, o princípio determina: "que cada um deve contribuir na proporção de suas rendas e haveres, independentemente de sua eventual disponibilidade financeira."12 Para Aliomar Baleeiro, "a capacidade contributiva do indivíduo significa sua idoneidade econômica para suportar, sem sacrifício do indispensável à vida compatível com a dignidade humana, uma fração qualquer do custo total dos serviços públicos."

\footnotetext{
${ }^{10}$ TIPKE, Klaus. "Princípio da Igualdade e a Idéia de Sistema no Direito Tributário", p. 517. LEHNER, Moris. "Considerações Econômicas e Tributação conforme a Capacidade Contributiva. Sobre a possibilidade de Uma Interpretação Teleológica de Normas com Finalidades Arrecadatórias”. In: SCHOUERI, Luiz Eduardo/ZILVETI, Fernando Aurélio (Coordenadores). Direito Tributário. Estudos em Homenagem a Brandão Machado. São Paulo: Dialética, 1998, p. 151.

${ }^{11}$ Não que sejam impossíveis distinções baseadas em outros critérios diversos da Capacidade Contributiva, como se demonstrará ao longo do texto, mas são as distinções reveladas pela manifestação de riqueza as que se fundamentam no princípio em estudo.

12 TORRES, Ricardo Lobo. Curso de Direito Financeiro e Tributário. 15. ed. Rio de Janeiro: Renovar, 2008 , p. 94.

${ }^{13}$ BALEEIRO, Aliomar. Uma Introdução à Ciência das Finanças. 14.ed. Rio de Janeiro: Forense, 1987, p. 259.
} 
Deste modo, a Capacidade Contributiva consiste na manifestação econômica identificada pelo legislador como signo presuntivo de riqueza a fundamentar a tributação.

Embora as expressões capacidade econômica e capacidade contributiva sejam utilizadas como sinônimas, é correta a distinção de Carrera Raya, ${ }^{14}$ segundo a qual a primeira designa a disponibilidade de riqueza, ou seja, de meios econômicos no plano fático, enquanto a última se refere à capacidade econômica eleita pelo legislador como fato gerador do tributo.

Como não é possível ao legislador identificar a capacidade contributiva de cada pessoa, ele visualiza situações que a revelam: são os fatos geradores dos impostos. Não que os demais tributos também não se subordinem ao princípio da Capacidade Contributiva, como abaixo se demonstrará, mas nos impostos, como tributo que não se vincula a uma atuação estatal, não há considerações baseadas no princípio do Custo-Benefício. É por esse motivo que a existência de um sistema tributário melhor atende ao princípio da Capacidade Contributiva, do que a idéia de imposto único, desde que, como é óbvio presumir, tal sistema seja concebido à luz de fatos geradores que se revelem em signos de presuntivos de riqueza e que sejam harmônicos entre si, e não por simplesmente se moldarem a uma arrecadação menos complexa.

Dentro da concepção de que o fato gerador se traduz em signo de manifestação de riqueza, o princípio desdobra-se em uma acepção objetiva em que se apresenta como fundamento da tributação e obrigatoriedade à eleição pelo legislador de um signo presuntivo de riqueza para compor a hipótese de incidência tributária; e outra subjetiva, destinado a graduar a tributação e apresentar limites máximos e mínimos ao seu desenvolvimento. ${ }^{15}$

Capacidade Contributiva:

I) Aspectos Objetivos:

a) fundamento da tributação;

b) obrigatoriedade de eleição de signo presuntivo de riqueza para a hipótese de incidência.

II) Aspectos Subjetivos:

\footnotetext{
${ }^{14}$ CARRERA RAYA, Francisco José. Manual de Derecho Financiero. Vol. I. Madrid: Tecnos, 1993, p. 92

${ }^{15}$ COSTA, Regina Helena. Princípio da Capacidade Contributiva. São Paulo: Malheiros, 1993, p. 29; DERZI, Misabel Abreu Machado. Notas de Atualização de BALEEIRO, Aliomar, Limitações Constitucionais ao Poder de Tributar. 7 ed. Rio de Janeiro: Forense, 1997, p. 691.
} 
a) graduação da tributação;

b) limites máximos e mínimos de tributação.

Em seu primeiro aspecto objetivo, a Capacidade Contributiva constitui fundamento constitucional para a exigência tributária, uma vez que não há tributação onde não há manifestação de riqueza. Ademais, o plano objetivo se completa pelo segundo aspecto, revelado na diretriz constitucionalmente firmada para a eleição pelo legislador de um fato gerador que seja revestido de conteúdo econômico. Tal dimensão objetiva será, portanto, violada quando houver tributação de atos que não se revelem em signos presuntivos de riqueza, como os do uso de barba e bigode, por exemplo. ${ }^{16}$

Deste modo, o princípio da Capacidade Contributiva em seu aspecto objetivo determina que os fatos geradores de cada imposto tenham origem nas duas espécies de riqueza existentes: a renda (dimensão pessoal) e o patrimônio (dimensão real). Os demais fatos geradores previstos no sistema tributário são constituídos como desdobramentos desses dois fenômenos econômicos; constituem eles técnicas diferentes para se atingir o mesmo resultado. Obviamente quando se reduzem os signos de manifestação de riqueza à renda e ao patrimônio, estas expressões são utilizadas em sentido bem mais amplo do que lhes são dados pela legislação que define os impostos diretamente incidentes sobre patrimônio e renda. Retrata bem essa visão a idéia de Pérez de Ayala. Segundo o Conde de Cedillo, a riqueza é manifestada por meio de uma visão fotográfica, e, portanto estática, pelo patrimônio. No entanto, a riqueza também pode ser visualizada por uma visão cinematográfica, dinâmica, a exigir uma delimitação temporal a determinado período. É o que ocorre com a renda. ${ }^{17}$ Assim, o sistema tributário prevê a tributação da renda bruta (receita bruta, prestação de serviços), da renda líquida (lucro), da renda aplicada a determinada finalidade (folha de

\footnotetext{
${ }^{16}$ JARACH, Dino. O Fato Imponível - Teoria Geral do Direito Tributário Substantivo. Traduzida por Dejalma de Campos, São Paulo: Revista dos Tribunais, 1989, p. 95/96: "Todas as situações e todos os fatos aos quais está vinculado o nascimento de uma obrigação impositiva possuem como característica a de apresentar um estado ou um movimento de riqueza; isto se comprova com a análise indutiva do direito positivo e corresponde ao critério financeiro que é próprio do imposto: o Estado exige uma soma de dinheiro em situações que indicam capacidade contributiva. É certo que o Estado por capricho, pelo seu poder de império, poderia exigir impostos com base em qualquer pressuposto de fato, mas o Estado, afortunadamente, não age assim". No mesmo sentido: UCKMAR, Victor. Princípios Comuns de Direito Constitucional Tributário. Trad. Marco Aurélio Greco. 2. ed. São Paulo: Malheiros, 1999, p. 83: "Ademais, o dimensionamento à capacidade contributiva exclui "graduações da carga tributária que não sejam relacionadas a diferenças na condição econômica dos indivíduos". Único elemento para diferenciar as cargas tributárias entre várias pessoas é a sua capacidade econômica: portanto, não seria consentido estabelecer que "os loiros devem pagar mais que os morenos" ou que todas as pessoas calvas ou míopes devam, enquanto tais, pagar um tributo" .

${ }^{17}$ PEREZ DE AYALA, Jose Luis. Derecho Tributario I, p. 89.
} 
salários). Tributa a alienação de patrimônio (circulação de bens, transmissão de bens) e a sua manutenção (propriedade, grandes fortunas).

Vale ainda ressaltar que, diante do binômio renda/patrimônio como signos presuntivos de riqueza, os impostos pessoais devem ter como fato gerador algum fenômeno que revele a renda disponível para a pessoa física e o lucro para as empresas. ${ }^{18}$ Nos impostos reais, a riqueza é revelada por dados do contribuinte relacionados com o patrimônio, estando a capacidade contributiva, neste caso, também associada à função social da propriedade, ${ }^{19}$ num ordenamento que não absolutiza os direitos do proprietário. A partir do advento do Estado Social, a função social da propriedade não é mais encarada como um limite extrínseco aos direitos do proprietário, mas como verdadeiro fundamento do direito à propriedade. Nesse sentido, uma de suas funções sociais seria a de contribuir, através de uma parcela de seus frutos, para o atendimento das despesas públicas. Assim, a tributação não pode atingir, senão, os rendimentos do patrimônio. ${ }^{20}$ Porém, não ofende o princípio da Igualdade a tributação dos rendimentos do capital de forma mais onerosa que os rendimentos do trabalho. Ao contrário, em face do primado constitucional do trabalho, trata-se de uma medida da mais alta Justiça. ${ }^{21}$

Por outro lado, é de acordo com seu primeiro aspecto subjetivo que o princípio se destina a aferir a capacidade de pagamento de cada um, graduando-a de acordo com o signo de manifestação de riqueza escolhido pelo legislador, ao definir o fato gerador de cada tributo. É nesse aspecto que se apresenta a maior dificuldade prática de efetivação da idéia de Capacidade Contributiva que, como princípio que é, apresenta grande fluidez em sua definição, constituindo verdadeiro conceito indeterminado, cujo núcleo é revelado pela riqueza disponível. ${ }^{22} \mathrm{E}$ essa indeterminação conceitual é enfrentada pela regulação legal de cada imposto, levando em consideração não só a definição do fato gerador em seus aspectos subjetivo, material, temporal, espacial e quantitativo, mas também os subprincípios da proporcionalidade, da progressividade, da seletividade e da personificação. ${ }^{23}$ É desta forma

\footnotetext{
18 TIPKE, Klaus. "Sobre a Unidade da Ordem Jurídica Tributária”. In: SCHOUERI, Luiz Eduardo/ZILVETI, Fernando Aurélio (Coordenadores). Direito Tributário. Estudos em Homenagem a Brandão Machado. São Paulo: Dialética, 1998, p. 64: "Todo o cidadão deve pagar impostos em conformidade com o montante de sua renda disponível para o pagamento de impostos; toda empresa deve pagar impostos de acordo com o montante de seu lucro".

${ }^{19}$ HERRERA MOLINA, Pedro Manuel. Capacidad Económica y Sistema Fiscal - Análisis del ordenamiento español a la luz del Derecho alemán. Barcelona: Marcial Pons, 1998, p. 94.

${ }^{20}$ TIPKE, Klaus. "Sobre a Unidade da Ordem Jurídica Tributária”, p. 63.

${ }^{21}$ TIPKE, Klaus. "Sobre a Unidade da Ordem Jurídica Tributária”, p. 65.

${ }^{22}$ HERRERA MOLINA. Capacidad Econômica y Sistema Fiscal - Análisis del ordenamiento español a la luz del Derecho alemán, p. 145.

${ }^{23}$ Os quatro subprincípios são elencados por Ricardo Lobo Torres (Curso de Direito Financeiro e Tributário, p. 94), que restringe a personificação aos limites personalização ou pessoalidade dos impostos pessoais. No entanto, em outra obra (Tratado de Direito Constitucional Financeiro e Tributário - Vol. II - Valores e
} 
que a riqueza disponível será revelada em atendimento ao aspecto subjetivo do princípio da Capacidade Contributiva.

Deste modo, são subprincípios da Capacidade Contributiva:

a) proporcionalidade;

b) progressividade;

c) seletividade; $\mathrm{e}$

d) personificação.

A proporcionalidade consiste na variação da tributação em razão da diferença da base de cálculo, a partir da aplicação da mesma alíquota. É o padrão clássico para efetivação da capacidade contributiva concebido por Adam Smith a partir da teoria do benefício, segundo a qual se presume que as pessoas se beneficiam das prestações estatais na proporção de suas riquezas. ${ }^{24}$ Contestada por Stuart Mill, a teoria do benefício encontrou oposição na teoria do igual sacrifício, que acabou por consagrar o subprincípio da progressividade como grande instrumento do Welfare State. Juntamente com este, no entanto, a progressividade começou a perder fôlego, a partir das décadas de 1970 e 1980, quando a teoria do benefício foi retomada James Buchanan, ${ }^{25}$ durante o apogeu do neoliberalismo. Nos dias atuais, a proporcionalidade é saudada como o melhor índice de capacidade contributiva por John Rawls ${ }^{26}$ e Klaus Tipke. ${ }^{27}$ Porém, mesmo sob a perspectiva liberal assumida por esses autores, é reconhecida a importância da progressividade como mecanismo de distribuição de renda ${ }^{28}$ no Estado Social. $^{29}$

A progressividade, por sua vez, se concretiza pela elevação da alíquota na medida em que é aumentada a base de cálculo. Seu fundamento era, originariamente, a distribuição igualitária do sacrifício social da tributação conforme defendido por Stuart Mill. O economista inglês partia teoria da utilidade marginal do capital, a partir da idéia de que a utilidade do capital para o seu possuidor diminui na medida do seu crescimento, sendo legítima sua apropriação pelo Estado em parcela maior.

Princípios Constitucionais Tributários. Rio de Janeiro: Renovar, 2005, p. 312-343), o autor trouxe outros subprincípios, como generalidade, universalidade, neutralidade, repercussão legal obrigatória, nãocumulatividade, país de destino. Preferimos a classificação anterior, exposta no texto, por entendermos serem os quatro princípios aqui elencados especificamente vinculados ao princípio da Capacidade Contributiva, enquanto os demais, no nosso pensar, se vinculam, de modo mais genérico, ao valor da Justiça Fiscal.

${ }^{24}$ SMITH, Adam. Riqueza das Nações. 3. ed. Lisboa: Calouste Gulberkian, 1999, Vol. II, p. 485.

${ }^{25}$ BUCHANAN, James. The Limits of Liberty - Between Anarchy and Leviathan. Chicago: The University of Chicago Press, 1975, p. 98.

${ }^{26}$ RAWLS, John. Uma Teoria da Justiça. São Paulo: Martins Fontes, 1997, p. 307.

${ }^{27}$ TIPKE, Klaus. "Princípio da Igualdade e a Idéia de Sistema no Direito Tributário", p. 527.

${ }^{28}$ RAWLS, John. Uma Teoria da Justiça, p. 308.

${ }^{29}$ TIPKE, Klaus. "Princípio da Igualdade e a Idéia de Sistema no Direito Tributário", p. 527. 
Após a retomada da teoria do benefício pelos economistas neoliberais do final do século $\mathrm{XX}$, a progressividade, hoje, não mais deve ser extraída de uma visão utilitarista de igual sacrifício, mas como importante instrumento de redistribuição de rendas no Estado Social e Democrático de Direito.

O próprio Rawls, embora defenda que os tributos com finalidade arrecadatória incidentes sobre as despesas ou rendas devam ser proporcionais em sociedades que já atingiram alto grau de respeito aos princípios da Justiça como eqüidade, uma vez que essa modalidade de tributação é mais adequada ao estímulo da produção, reconhece também que nos sistemas tributários de países em que haja maior desigualdade social, a progressividade dos impostos sobre a renda é medida exigida pelos princípios da Liberdade, da Igualdade eqüitativa de oportunidades e da diferença. ${ }^{30}$ Nesse mesmo sentido, Tipke entende, na esteira do Tribunal Constitucional Alemão, que a progressividade rompe com a Igualdade, mas este rompimento é justificado pelo princípio do Estado Social, que tem por objetivo a distribuição de riquezas. $^{31}$

Deste modo, numa sociedade marcada por profundas desigualdades sociais como a nossa, a progressividade é, em vários impostos, o instrumento mais adequado à aplicação do princípio da Capacidade Contributiva, baseando-se na Solidariedade e na Justiça Social. É que a proporcionalidade, embora revele manifestação da capacidade contributiva, uma vez que não adota um valor fixo na tributação, se traduz num instrumento bastante tímido na distribuição de rendas, limitando-se a garantir a Igualdade formal entre os cidadãos, o que no Estado Social revela-se insuficiente. Ademais, como bem observa Luciano Amaro, ${ }^{32}$ a Capacidade Contributiva não se esgota na proporcionalidade, uma vez que aquela exige "a justiça da incidência em cada situação isoladamente considerada e não apenas a justiça relativa entre uma e outra das duas situações."

No mesmo sentido, Pedro Herrera Molina, para quem é a progressividade que confere conteúdo ao princípio da Capacidade Contributiva, uma vez que aquela deriva dos valores da Igualdade $^{33}$ e da Solidariedade.

No entanto, o Supremo Tribunal Federal vem entendendo que a progressividade não é decorrência natural do princípio da Capacidade Contributiva, que por sua vez, se realiza normalmente pela proporcionalidade, a não ser que o próprio texto constitucional determine

\footnotetext{
${ }^{30}$ RAWLS, John. Uma Teoria da Justiça, p. 308.

${ }^{31}$ TIPKE, Klaus. "Princípio da Igualdade e a Idéia de Sistema no Direito Tributário", p. 527.

${ }^{32}$ AMARO, Luciano. Direito Tributário Brasileiro. 16. ed. São Paulo: Saraiva, 2010, p. 165.

${ }^{33}$ Contra: TIPKE, Klaus. "Princípio da Igualdade e a Idéia de Sistema no Direito Tributário", p. 527, para quem a Igualdade é mais bem atendida pela proporcionalidade.
} 
expressamente a utilização de alíquotas progressivas. ${ }^{34}$ A consagração no STF da tese da necessidade de previsão constitucional expressa para a aplicação da progressividade faz com que este subprincípio, como instrumento realizador da Capacidade Contributiva, se limite ao imposto de renda, ao IPTU (após a EC n 29/00) e ao ITR (após a EC nº 42/03). Porém, vale destacar que a nova composição do STF pode promover uma salutar modificação nesse posicionamento, a partir da idéia de que a progressividade é uma decorrência do princípio da Capacidade Contributiva, sendo aplicável a todos os impostos. ${ }^{35}$

É que a posição de condicionar a aplicação da progressividade à expressa previsão constitucional esvazia mortalmente o princípio da Capacidade Contributiva, que encontra, no Estado Social e Democrático de Direito, a progressividade como mecanismo mais eficaz para sua realização, mormente numa sociedade tão desigual quanto a brasileira.

Por outro lado, também já entendeu o STF pela impossibilidade de aplicação de alíquotas progressivas nos impostos reais. ${ }^{36}$ No entanto, nos parece inexistir qualquer óbice à progressividade dos impostos reais, uma vez que o patrimônio do contribuinte é índice de riqueza hábil a ser quantificado na fixação do aspecto subjetivo do princípio da Capacidade Contributiva, como se extrai do próprio art. 145, $\S 1^{\circ}$ da Constituição Federal, e, mais recentemente, da EC no 29/00, que, dando nova redação ao art. 156, $\S 1^{\text {o }}$ do Texto Maior, previu a progressividade no IPTU, vinculada à Capacidade Contributiva e calculada em razão do valor venal do imóvel. ${ }^{37}$ Caso o STF acolha a correção legislativa da jurisprudência, aceitando a progressividade do IPTU após a EC no $29 / 00^{38}$ não haverá mais espaço na sua

\footnotetext{
${ }^{34}$ STF, Súmula $n^{\circ}$ 668: "É inconstitucional a lei municipal que tenha estabelecido, antes da Emenda Constitucional 29/2000, alíquotas progressivas de IPTU, salvo se destinada a assegurar o cumprimento da função social da propriedade urbana"; STF, Súmula $\mathrm{n}^{\circ}$ 656: É inconstitucional a lei que estabelece alíquotas progressivas para o imposto de transmissão inter vivos de bens imóveis - ITBI com base no valor venal do imóvel." Precedentes: Em relação ao IPTU: STF, Pleno, ADI n ${ }^{\circ}$ 2.010-2/DF, Rel. Min. Celso Mello, DJU 12/04/2002, p. 51. STF, Pleno, RE no 153.771/MG, Rel. Min. Moreira Alves, DJU de 05/09/97, p. 41.892. Em relação ao ITBI: STF, Pleno, RE n ${ }^{\circ}$ 234.105/SP. Rel. Min. Carlos Velloso, DJU de 31/03/00, p. 61.

${ }^{35}$ STF, Pleno, RE no 562.045/RS, Rel. Ricardo Lewandowski, Informativo STF no 520 . No caso em questão, o Tribunal julga a constitucionalidade de lei estadual gaúcha que promoveu a progressividade baseada no valor venal dos imóveis no ITD, imposto sobre transmissões causa mortis e doações. Após o voto do relator que, na esteira da jurisprudência até agora dominante na Corte, considerou inaplicável a progressividade, o Ministro Eros Grau abriu divergência, sendo acompanhado pelos Ministros Menezes Direito, Cármen Lúcia e Joaquim Barbosa, admitindo a progressividade como uma manifestação da Capacidade Contributiva em todos os impostos. Pediu vista o Ministro Carlos Britto na sessão do dia 17/09/2008.

${ }^{36}$ STF, Pleno, RE no 153.771/MG, Rel. Min. Carlos Velloso. Rel. p/acórdão: Min. Moreira Alves, DJU de 05/09/97, p. 41.892. No mesmo sentido: TORRES, Ricardo Lobo. Tratado de Direito Constitucional Financeiro e Tributário, Vol.II, p. 317.

${ }^{37}$ Já existem importantes vozes que se levantam contra a constitucionalidade do IPTU progressivo previsto na EC n ${ }^{\circ}$ 29/00. Por todos: TORRES, Ricardo Lobo. Tratado de Direito Constitucional Financeiro e Tributário, Vol.II, p. 318. No entanto, entendemos não ter a referida emenda constitucional, nesse ponto, violado qualquer cláusula pétrea, sendo compatível com nossa Lei Maior, pelas razões expostas no texto.

${ }^{38}$ STF, Pleno, RE no 423.768, Rel. Min. Marco Aurélio, Informativo STF $n^{\circ}$ 433. No julgado, o relator acolheu a progressividade do IPTU estabelecida pela EC n ${ }^{\circ}$ 29/00, no que foi acompanhado pelos Ministros Cármen
} 
jurisprudência para a alegação de que o imposto real não pode ser progressivo, o que seria altamente positivo, haja vista que a distinção entre impostos pessoais e reais é muito mais cara à Ciência das Finanças do que ao Direito Tributário, não tendo a importância constitucional a ela conferida.

É importante destacar que a partir da EC no 29/00 o constituinte adotou uma nomenclatura distinta para a diferenciação de alíquotas baseada na Capacidade Contributiva, a que denominou progressividade, daquela fundada em razões extrafiscais, cuidado que não teve o constituinte originário. Não foi por outro motivo que a topografia adotada pela EC $n^{\circ}$ 29/00, que deu nova redação ao $\S 1^{\circ}$ do art. 156, CF, separou os dois fenômenos em incisos diversos. No inciso I está a progressividade do IPTU baseada no valor venal (capacidade contributiva) e no inciso segundo a diferenciação em razão da localização e do uso do imóvel (extrafiscalidade), que alguns já vem denominando de seletividade do IPTU. ${ }^{39}$ Porém, a seletividade, como a seguir se demonstrará, se revela pela essencialidade do bem, o que não atende só a extrafiscalidade, mas também à capacidade contributiva dos impostos indiretos. Portanto, o neologismo mais atrapalha do que ajuda. Aceitas essas premissas, a diferenciação de alíquota poderá se fundar na progressividade (capacidade contributiva), na extrafiscalidade ou na seletividade (capacidade contributiva + extrafiscalidade). A mesma distinção foi adotada pela $\mathrm{EC} \mathrm{n}^{\circ}$ 42/03 ao estabelecer a progressividade do ITR, que não se confunde com a diferenciação de alíquotas destinada a estimular o cumprimento da função social da propriedade rural.

Assim, no Estado Social e Democrático de Direito, a proporcionalidade convide em harmonia com a progressividade, a primeira como decorrência da Igualdade formal e a segunda como mecanismo de distribuição de riquezas. As duas técnicas, decorrentes do princípio da Capacidade Contributiva, podem ser, de acordo com a natureza do imposto, aplicadas pelo legislador, independentemente de previsão constitucional expressa.

A seletividade se materializa pela variação de alíquotas em função da essencialidade do produto ou da mercadoria, e representa a modalidade mais adequada à aplicação do princípio da Capacidade Contributiva aos impostos indiretos, como o ICMS e o IPI, pois afere o índice de riqueza do contribuinte de fato, a partir do grau de indispensabilidade do bem consumido. Dentro dessa lógica, o consumo de bens populares é gravado com alíquotas

\footnotetext{
Lúcia, Eros Grau, Joaquim Barbosa e Sepúlveda Pertence. O Ministro Carlos Britto pediu vista na sessão de 28/06/2006.

39 MACHADO, Hugo de Brito, Curso de Direito Tributário. 30. ed. São Paulo: Malheiros, 2009, p. 396; TORRES, Ricardo Lobo. Curso de Direito Financeiro e Tributário, p. 397.
} 
menores, como ocorre com os produtos da cesta básica. Já os bens supérfluos são tributados com base em alíquotas maiores, como se dá com cigarros, bebidas e perfumes.

Em sendo assim, não é difícil perceber que a aplicação da proporcionalidade nos impostos incidentes sobre os bens de consumo popular, como gêneros alimentícios de primeira necessidade, acaba gerando um efeito regressivo, pois retira das classes menos aquinhoadas, relativamente mais do que é suportado pelos abastados, ${ }^{40}$ não se resguardando o mínimo existencial.

Por sua vez, situação parecida ocorreria na aplicação da progressividade aos impostos sobre o consumo, uma vez que não suportando o sujeito ativo a carga tributária, a tributação de acordo com a sua riqueza teria o condão de transferir para o consumidor, contribuinte de fato, um encargo que não seria necessariamente adequado à sua capacidade contributiva. ${ }^{41}$

A personificação determina que o legislador leve em consideração dados relativos ao contribuinte, relativos ao seu patrimônio e renda, ou na dicção constitucional do $\S 1^{\circ}$ do art. 145, CF, patrimônio, rendimentos e atividades econômicas do contribuinte, para mensurar a tributação, desprezando aspectos relativos a atividades estatais a ele prestadas. É a manifestação de capacidade contributiva nos impostos, englobando não só aqueles classificados como pessoais, mas também os reais, uma vez que o patrimônio como expressão econômica dos direitos da personalidade, ${ }^{42}$ também personifica a riqueza do contribuinte. A aplicação da personificação aos impostos pessoais é revelada pelo subprincípio da pessoalidade ou da personalização, a partir de dados vinculados à renda (riqueza dinâmica), e não ao patrimônio (riqueza estática). É o que ocorre no imposto de renda, por exemplo, com as deduções de despesas com dependentes, médicas, e de instrução. Como parece óbvio, são nos impostos pessoais que o subprincípio da pessoalidade terá aplicabilidade plena. Daí a dicção constitucional do sempre que possível. Porém, há hoje uma tendência à pessoalidade também dos impostos reais, quando o legislador leva em consideração dados intrínsecos à vida do contribuinte, como se dá na isenção de IPTU para ex-combatentes e aposentados que percebam até determinada renda. Embora tais medidas não importem na transformação do aludido tributo em um imposto pessoal, vez que suas características principais continuam

\footnotetext{
${ }^{40}$ BALEEIRO, Aliomar. Uma Introdução às Ciências das Finanças, p. 211.

${ }^{41}$ VALDÉS COSTA, Ramón. Instituciones de Derecho Tributario. Buenos Aires: Depalma, 1996, p. 455.

${ }^{42}$ PEREIRA, Caio Mário da Silva. Instituições de Direito Civil, Vol. I. 10. ed. Rio de Janeiro: Forense, 1987, p. 157. No mesmo sentido: DANTAS, San Tiago. Programa de Direito Civil - Teoria Geral. Taquifragado por Victo Bourhis Jürgens. Revista e atualizada por Gustavo Tepedino, Antônio Carlos de Sá, Carlos Edison do Rêgo Monteiro Filho e Renan Miguel Saad. 3. ed. Rio de Janeiro: Forense, 2001, p. 153.
} 
vinculadas ao bem imóvel, há dados de pessoalidade que prestigiam o referido princípio constitucional.

Vale ainda advertir que no plano subjetivo do princípio da Capacidade Contributiva, além do primeiro aspecto revelado pelo critério de graduação da tributação, o que lhe confere uma dimensão horizontal a permitir a diferenciação de um contribuinte em relação aos demais, há também uma dimensão vertical, a ser exercida em relação ao Estado, por meio da fixação de limites, ${ }^{43}$ seja no patamar inferior, por meio do mínimo existencial, seja na esfera superior pela vedação ao confisco, que se revelam como verdadeiras fronteiras delimitadoras do referido princípio em suas porções mínimas e máximas, no que se realiza o seu segundo aspecto subjetivo. Não se pode tributar abaixo do mínimo existencial, pois não há riqueza disponível. Não se tributa acima dos limites confiscatórios, onde a seara da capacidade contributiva exaure-se.

Embora não possua dicção constitucional própria, o mínimo existencial deriva, segundo Ricardo Lobo Torres, ${ }^{44}$ da idéia de Liberdade, de Igualdade e dos direitos humanos, e tem seus contornos definidos pela linha que separa a vida simples do cidadão humilde da pobreza absoluta que deve ser combatida pelo Estado, não só por meio de abstenção na tributação, como também por prestações positivas, envolvendo além dos direitos individuais, os sociais, relativos à saúde, à alimentação, à educação e à assistência social. Assim, no campo tributário, o mínimo existencial deixa o contribuinte livre de qualquer tributação até o limite em que sejam atendidos os requisitos mínimos para uma vida humana digna. ${ }^{45}$

De acordo com Klaus Tipke, o mínimo existencial não deve ser fixado em patamar inferior ao estabelecido como benefício de aposentadoria, pois, em regra, o cidadão ativo possui mais necessidades vitais que o aposentado. ${ }^{46}$ Sustenta ainda o professor emérito da Universidade de Colônia que o mínimo existencial não se aplica somente ao imposto de renda, mas a todos os tributos, e que as parcelas que ficarem isentas do imposto de renda não podem ser tributadas por impostos especiais. ${ }^{47}$ Por seu turno, os impostos indiretos também

\footnotetext{
${ }^{43}$ TORRES, Ricardo Lobo. Tratado de Direito Constitucional, Financeiro e Tributário, Vol. II, p. 304

${ }^{44}$ TORRES, Ricardo Lobo. Tratado de Direito Constitucional, Financeiro e Tributário, Vol. III. 2. ed. Rio de Janeiro: Renovar, 1999, p. 146.

${ }^{45}$ LEHNER, Moris. Considerações Econômicas e Tributação conforme a Capacidade Contributiva. Sobre a possibilidade de Uma Interpretação Teleológica de Normas com Finalidades Arrecadatórias”, p. 151, citando precedente do Tribunal Constitucional Alemão que delineou os contornos do mínimo existencial.

46 TIPKE, Klaus. "Sobre a Unidade da Ordem Jurídica Tributária", p. 61. No mesmo sentido: HERRERA MOLINA, Pedro M. Capacidad Econômica y Sistema Fiscal - Análisis del ordenamiento español a la luz del Derecho aléman, p. 144.

${ }^{47}$ TIPKE, Klaus. "Sobre a Unidade da Ordem Jurídica Tributária”, p. 67.
} 
devem respeitar o mínimo existencial, o que é viabilizado pelo mecanismo da seletividade e por meio da isenção dos bens de primeira necessidade. ${ }^{48}$

No outro extremo, como limite máximo da tributação de acordo com a Capacidade Contributiva encontra-se o princípio da vedação ao confisco que deriva do próprio direito de propriedade. $^{49}$

Em resumo, em seu aspecto objetivo, a Capacidade Contributiva funciona como fundamento jurídico do tributo e como diretriz para eleição da hipótese de incidência. Em sua dimensão subjetiva, como critério de graduação do tributo e limite à tributação. ${ }^{50}$

\section{3) Eficácia e Extensão do Princípio da Capacidade Contributiva}

Quanto à sua eficácia, a Capacidade Contributiva é princípio cogente, ${ }^{51}$ obrigando não só ao legislador, mas também ao aplicador da lei, seja por meio da atividade regulamentar ou jurisdicional. Podemos vislumbrar esta característica quando o Poder Judiciário afasta a aplicação de uma regra concessiva de uma isenção que propicie um privilégio odioso; ${ }^{52}$ ou, no reconhecimento pelo juiz de que, embora o tributo esteja previsto em lei, determinado segmento de contribuintes não revela capacidade contributiva para suportá-lo, por ter sido violado o mínimo existencial, ou por aquela situação, definida em lei como reveladora de riqueza, não produzir esse efeito em relação ao segmento considerado.

No entanto, tal possibilidade não habilita o juiz, no caso concreto, a reconhecer a ausência de capacidade contributiva de determinado contribuinte individual quando a lei, em sua acepção genérica, não se revelar violadora do princípio. Se o tributo é fixado de forma adequada ao signo de manifestação de riqueza revelado pelo fato gerador previsto em lei, a

\footnotetext{
${ }^{48}$ HERRERA MOLINA, Pedro M. Capacidad Econômica y Sistema Fiscal - Análisis del ordenamiento español a la luz del Derecho aléman, p. 144.

${ }^{49}$ VOGEL, Klaus. "Tributos Regulatórios e Garantia da Propriedade no Direito Constitucional da República Federal da Alemanha”. In: Brandão Machado (coord.). Estudos em Homenagem ao Prof. Ruy Barbosa Nogueira. São Paulo: Saraiva, 1984, p. 550, onde o autor alemão informa que naquele país, dada a inexistência de dispositivo constitucional expresso que proíba a tributação confiscatória, o excesso tributário é vedado pelo art. 14 da Lei Fundamental, que consagra o direito de propriedade.

${ }^{50}$ COSTA, Regina Helena. Princípio da Capacidade Contributiva, p. 29; DERZI, Misabel Abreu Machado. Notas de Atualização de BALEEIRO, Aliomar, Limitações Constitucionais ao Poder de Tributar, p. 691.

${ }^{51}$ Como adverte Carrera Raya, está inteiramente superada historicamente a tendência de se considerar a Capacidade Contributiva um princípio programático (CARRERA RAYA. Francisco José. Manual de Derecho Financiero, Vol. I, p. 94).

${ }^{52}$ Sobre o conceito de privilégio odioso, vide TORRES, Ricardo Lobo. Tratado de Direito Constitucional, Financeiro e Tributário. Vol. III, p. 341.
} 
exclusão de determinado contribuinte por razões individuais consagraria um privilégio odioso. ${ }^{53}$ O mesmo não ocorre quando a aplicação da norma se revela inconstitucional para determinado grupo de contribuintes, em sentido genérico. Neste caso, tal norma não deve ser aplicada a esse grupo, sendo válida em relação aos seus demais destinatários. Porém, é evidente que a demonstração cabal por determinado contribuinte de que a Capacidade Contributiva é desatendida no caso concreto constitui indício relevante de que o critério de graduação do tributo elegido pelo legislador não é compatível com a exigência constitucional do art. $145, \S 1^{\circ}$.

Também não parece possível a modificação judicial da alíquota do tributo pela declaração parcial de inconstitucionalidade da lei tributária, por apenas em parte superar a Capacidade Contributiva. ${ }^{54}$ Se a tributação tornou-se excessiva em razão de um aumento de alíquota, a declaração de inconstitucionalidade da lei que o majorou teria o condão de restabelecer a legislação anterior à modificação. No entanto, se a fixação desmedida do tributo se der por ocasião de sua instituição primeira, não restará solução senão a declaração de inconstitucionalidade da exação. Caso o Poder Judiciário pudesse reduzir a alíquota do tributo, estaria estabelecendo regra não prevista pelo Poder Legislativo, invadindo o espaço de conformação deste e legislando positivamente.

A expressão sempre que possível, contida no art. $145, \S 1^{\circ}, \mathrm{CF}$, se refere ao princípio da pessoalidade, como vimos, não se aplicando ao princípio da Capacidade Contributiva, cuja consideração sempre será levada em conta. ${ }^{55}$ Há quem entenda que a expressão constitucional abriria espaço à extrafiscalidade nos impostos. ${ }^{56}$ Porém, a tributação extrafiscal não afasta a Capacidade Contributiva, sendo com ela ponderada. ${ }^{57}$ Já houve também a associação da expressão sempre que possível à exclusão do princípio em relação aos impostos reais, em algumas decisões que vedaram a aplicação da progressividade ao IPTU. ${ }^{58}$ Tal posicionamento jurisprudencial, que nunca chegou a ser majoritário quanto ao seu fundamento excludente da Capacidade Contributiva em relação aos impostos reais, partiu de

\footnotetext{
${ }^{53}$ Contra: OLIVEIRA, José Marcos Domingues. Direito Tributário - Capacidade Contributiva. 2. ed. Rio de Janeiro: Renovar, 1998, p. 147, que sustenta a possibilidade de a lei ser considerada constitucional em sentido genérico, mas ser violadora da Capacidade Contributiva de determinado contribuinte.

${ }_{54}^{54}$ Contra: OLIVEIRA, José Marcos Domingues. Direito Tributário - Capacidade Contributiva, p. 155.

${ }^{55}$ MACHADO, Hugo de Brito, Curso de Direito Tributário, p. 40; ZILVETI, Fernando Aurélio. Princípios de Direito Tributário e a Capacidade Contributiva. São Paulo: Quartier Latin, 2004, p. 254; ROSA JR., Luiz Emydio da. Manual de Direito Financeiro e Tributário. 17. ed. Rio de Janeiro: Renovar, 2003, p. 338. Contra: AMARO, Luciano. Direito Tributário Brasileiro, p. 164;

${ }^{56}$ Sistema Constitucional Tributário. São Paulo: Saraiva, 2004, p. 360.

${ }^{57}$ RIBEIRO, Ricardo Lodi. Justiça, Interpretação e Elisão Tributária. Rio de Janeiro: Lumen Juris, 2003, p. 81.

${ }^{58}$ STF, Pleno, RE no 153.771/MG, Rel. Min. Carlos Velloso. Rel. p/acórdão: Min. Moreira Alves, DJU de 05/09/97, p. 41.892.
} 
uma interpretação equivocada do pensamento da corrente doutrinária que nega a aplicação da progressividade nos impostos reais por entender que nestes, a Capacidade Contributiva é atendida pela proporcionalidade. ${ }^{59}$ Porém, como se viu, o princípio da Capacidade Contributiva, por meio da personificação - que não se confunde com a pessoalidade dos impostos pessoais - deve ser aplicada a todos os impostos, sejam eles reais ou pessoais. O mesmo se dá em relação ao subprincípio da progressividade.

Quanto à sua extensão, como vimos, o princípio não se aplica apenas aos impostos, como podem imaginar os intérpretes mais apressados do art. $145, \S 1^{\circ}$ da Constituição Federal. Se a Capacidade Contributiva deriva da Igualdade, deve ser aplicada mesmo quando não prevista expressamente na constituição, como é o caso da Alemanha, e do Brasil de 1965 a 1988. Por esse motivo, não se pode afastar sua aplicação em relação aos demais tributos pelo simples fato do texto constitucional utilizar a expressão impostos, ao invés da palavra tributos. ${ }^{60}$ Embora a Constituição se refira somente aos impostos, uma vez que nesta espécie tributária só há a riqueza do contribuinte a se mensurar, sem considerações relativas às atividades estatais relativas ao contribuinte, o princípio também é aplicado aos tributos vinculados, como a taxa, conforme já reconheceu o $\mathrm{STF}^{61}$ e a contribuição de melhoria. Assim, a limitação contida no $\S 1^{\circ}$ do art. $145, \mathrm{CF}$ à aplicação do princípio, restringindo-o aos impostos diz respeito ao subprincípio da personificação, índice de capacidade contributiva relativo aos tributos não-vinculados a uma atividade estatal em relação à pessoa do contribuinte, e não ao próprio princípio da Capacidade Contributiva.

É bem verdade que nos impostos, dado o seu caráter de tributo não vinculado, o princípio tem uma acepção mais ampla. Afinal, não havendo atividade estatal a se mensurar, o único critério quantitativo a ser levado em conta pelo legislador é a riqueza do contribuinte por meio da personificação, seja nos impostos pessoais, por meio da pessoalidade, seja nos reais.

Mas isso não significa que os demais tributos não se subordinem ao referido princípio. Ao contrário, todas as espécies tributárias são por ele iluminadas. Em sua acepção objetiva, é

\footnotetext{
${ }^{59}$ Contra a progressividade dos impostos reais: TORRES, Ricardo Lobo. Tratado de Direito Constitucional, Financeiro e Tributário. Vol. II, p. 309.

${ }^{60}$ CONTI, José Maurício. Princípios Tributários da Capacidade Contributiva e da Progressividade. São Paulo: Dialética, 1997, p. 65; AMARO, Luciano. Direito Tributário Brasileiro, p. 166; MACHADO, Hugo de Brito, Curso de Direito Tributário, p. 40. OLIVEIRA, José Marcos Domingues. Direito Tributário - Capacidade Contributiva, p. 91. Contra: TORRES, Ricardo Lobo. Tratado de Direito Constitucional, Financeiro e Tributário. Vol. II, p. 309; ÁVILA, Humberto. Sistema Constitucional Tributário, p. 385; DERZI, Misabel Abreu Machado. Notas de Atualização de BALEEIRO, Aliomar, Limitações Constitucionais ao Poder de Tributar, p. 695; COSTA, Regina Helena. Princípio da Capacidade Contributiva. São Paulo: Malheiros, 1993, p. 52-60.

${ }^{61}$ STF, Pleno, RE no 177.835/PE, Rel. Min. Carlos Velloso, DJU de 25/05/2001, p 18.
} 
fácil constatar que todos os tributos devem ter como fundamento a manifestação de riqueza do contribuinte e ter o seu fato gerador escolhido entre os signos presuntivos dessa riqueza. Assim, mesmo nas taxas o fato gerador do tributo não pode ser uma conduta do contribuinte que não possua conteúdo econômico, como por exemplo, poluir o meio ambiente. ${ }^{62}$ Sob o prisma subjetivo, todos os tributos também devem respeitar os limites do mínimo existencial e do Não-confisco. Assim, a isenção de taxas e contribuições de melhoria dos contribuintes que, embora praticando o fato gerador vinculado a atividade estatal, serão desonerados face à hipossuficiência econômica, não tem outra origem que não o princípio da Capacidade Contributiva. ${ }^{63}$ É o que ocorre no fornecimento gratuito de certidões de óbito e no registro do casamento civil para os comprovadamente pobres (art. $5^{\circ}$, LXXVI, da Constituição Federal). ${ }^{64}$

Porém, em relação aos critérios de graduação dos tributos, segundo elemento objetivo da Capacidade Contributiva, é que a doutrina que nega a aplicação do referido princípio aos tributos vinculados apresenta seu melhor argumento. Alegam que a inaplicabilidade do princípio decorre da necessidade de a base de cálculo desses tributos guardarem referibilidade com a atuação estatal, com base no princípio do Custo-Benefício. ${ }^{65}$ Porém, não se pode esquecer que no Estado Social e Democrático de Direito, a Capacidade Contributiva não se esgota na Solidariedade Social. Esta tem como base a Justiça distributiva do Estado Social e serve de fundamento à personificação, critério aplicável aos impostos, e que determina ao legislador a identificação da renda do contribuinte (em todas as suas dimensões) nos impostos pessoais, bem como do seu patrimônio nos impostos reais. A Capacidade Contributiva contempla também o princípio do Custo-Benefício, fundado na Justiça comutativa do Estado Liberal, por meio da referibilidade das taxas e contribuições de melhoria. Porém, nos dias atuais, aparece ainda uma terceira figura, onde restam fundidos os valores da Justiça comutativa com os da Justiça distributiva. É a Solidariedade de Grupo (ou Custo-Benefício coletivo) que fundamenta a referibilidade de grupo nas contribuições parafiscais. ${ }^{66}$

Diante disso, fica evidenciado que a graduação das taxas com base na Capacidade Contributiva utiliza-se da própria referibilidade entre a atividade estatal vinculada ao fato

\footnotetext{
${ }^{62}$ STF, Pleno, ADI 2.178 MC/DF, Rel. Min. Ilmar Galvão, DJU 12/05/2000, p. 19, onde o Tribunal, embora não analisando a questão à luz da Capacidade Contributiva, entendeu que o ato de poluir não pode ser fato gerador de taxa ambiental. Como restou assentado em julgamento posterior (STF, Pleno, RE $n^{\circ}$ 453.464, Rel. Carlos Velloso, Informativo $\left.\mathrm{n}^{\circ} 396, \mathrm{j} .10 / 08 / 2005\right)$, a taxa ambiental deve ter como fato gerador uma atividade econômica do contribuinte que demande o exercício regular do poder de política ambiental.

${ }^{63}$ COÊLHO, Sacha Calmon Navarro. Comentários à Constituição de 1988 - Sistema Tributário. 3. ed. Rio de Janeiro: Forense, 1991, p. 46.

${ }^{64}$ SEIXAS FILHO, Aurélio. Taxa - Doutrina, Prática e Jurisprudência. Rio de Janeiro: Forense, 1990, p. 58.

${ }^{65}$ Por todos: TORRES, Ricardo Lobo. Tratado de Direito Constitucional, Financeiro e Tributário. Vol. II, p. 309.

${ }^{66}$ Vide item 1 deste artigo.
} 
gerador e a atuação do contribuinte identificada pelo legislador como núcleo dessa hipótese de incidência. Por outro lado, o aspecto quantitativo desse fato gerador, revelado pela base de cálculo e pela alíquota, tem que ser proporcional à complexidade e à onerosidade da atividade estatal. É aqui que exsurge a capacidade contributiva, como já foi reconhecido pelo STF no julgamento da Taxa de Fiscalização da CVM. ${ }^{67}$ No referido julgado, a Corte Maior identificou a capacidade contributiva em decorrência da maior complexidade e onerosidade da atividade estatal, pois as empresas que demandavam maior fiscalização, de acordo com o critério adotado pelo legislador, eram as empresas de maior patrimônio líquido, o que não deixa de ser um signo de maior manifestação de riqueza. Porém, é essencial que o critério de distinção escolhido pelo legislador para mensurar a taxa leve em consideração a própria referibilidade que, embora fundada no princípio do Custo-Benefício, não afasta a aplicação da Capacidade Contributiva. É que, como vimos, não existe oposição entre os princípios da Capacidade Contributiva e do Custo-Benefício. Ao contrário, nos tributos vinculados a uma atividade estatal específica em relação à pessoa do contribuinte, como a taxa e a contribuição de melhoria, a Capacidade Contributiva se manifesta pela relação custo-benefício, uma vez que o fato gerador desses tributos, que irá determinar o índice de manifestação de riqueza eleito pelo legislador para ser tributado, está intimamente relacionado com a atividade estatal.

Quanto às contribuições parafiscais e empréstimos compulsórios, que não possuam fatos geradores próprios, uma vez que se utilizam daqueles típicos aos impostos e taxas, assim como esses, deverão respeitar a Capacidade Contributiva, nos termos acima definidos para cada uma dessas duas espécies. ${ }^{68}$

Porém, cumpre destacar que nas contribuições parafiscais, embora o fato gerador não seja previamente conhecido, pois, ora adota-se o fato gerador do imposto, ora se adota o fato gerador da taxa, a necessidade de afetação das receitas às finalidades específicas, estabelece, qualquer que seja o fato gerador, com base no custo-benefício, uma relação entre a atividade estatal custeada pela contribuição e o grupo integrado pelo contribuinte. O princípio do Custo-Benefício na perspectiva coletiva fundamenta a referibilidade de grupo, a partir da destinação da contribuição a uma atividade estatal que se relaciona com o grupo que o contribuinte participa. Lançando a referibilidade de grupo raízes na idéia de Solidariedade de Grupo se liga assim à Capacidade Contributiva, uma vez que a atividade desempenhada pelo contribuinte deve se traduzir em signo presuntivo de riqueza que irá custear prestações estatais relacionadas ao grupo que ele participa. Como se vê, a referibilidade de grupo nas

\footnotetext{
${ }^{67}$ STF, Pleno, RE no 177.835/PE, Rel. Min. Carlos Velloso, DJU de 25/05/2001, p 18.

${ }^{68}$ OLIVEIRA, José Marcos Domingues. Direito Tributário - Capacidade Contributiva, p. 112.
} 
contribuições parafiscais é a manifestação de Capacidade Contributiva a ser atingida pelo legislador. Assim, a atividade estatal financiada pela contribuição parafiscal deve de relacionar com o grupo integrado pelo contribuinte. ${ }^{69}$ Aqui a referibilidade (que na taxa é individual) passa a ser coletiva, deslocando-se do núcleo do fato gerador para o seu aspecto finalístico. No entanto, a apreciação do núcleo do fato gerador não é irrelevante, uma vez que, em geral, é esse elemento que vai revelar o grupo de contribuintes que pratica a conduta legalmente escolhida como fato gerador. Devendo os aspectos nuclear, subjetivo e finalístico do fato gerador ser harmônicos entre si, é essencial para a caracterização da contribuição (o que irá determinar a sua validade caso o tributo não possa sobreviver como imposto ou taxa), a existência da referibilidade de grupo, revelada pela relação entre a finalidade e os contribuintes. Essa relação, por ser relativa ao grupo, é menos intensa do que a individualidade da taxa, mas sempre deve ser identificada, pelo menos, por uma normatização, regulação, fomento ou fiscalização próprias a esse segmento.

Portanto, viola a Capacidade Contributiva uma contribuição destinada a uma finalidade que não guarde referibilidade de grupo com os seus contribuintes, como é o caso da contribuição para o Funrural (Fundo de Assistência ao Trabalhador Rural), exigido de empresas urbanas. No entanto, o STF, confundindo a solidariedade de grupo com a solidariedade geral, considerou constitucional a exigência. ${ }^{70}$

\section{4) Conclusão}

Diante de todo o exposto, fica evidenciado que a Capacidade Contributiva, como critério de realização da Justiça Fiscal, não se apresenta apenas nos impostos. Em todos os tributos a Capacidade Contributiva atua, sob o aspecto objetivo, como fundamento da tributação e como obrigatoriedade de eleição pelo legislador de fato gerador que se revele como signo presuntivo de riqueza. Em seu aspecto subjetivo, também em todos os tributos, o princípio estabelece limites máximos e mínimos de tributação, com base no mínimo existencial e no não-confisco. Em todos esses elementos a aplicação do princípio nas cinco espécies tributárias não apresenta grandes distinções.

\footnotetext{
69 RIBEIRO, Ricardo Lodi. “As Contribuições Parafiscais e a Validação Constitucional das Espécies Tributárias", p. 118-119.

${ }^{70}$ STF, $1^{\text {a }}$ Turma, AI no 334.360 AgR, Rel. Min. Sepúlveda Pertence, DJU 25/02/2005, p. 19.; STF, $2^{\text {a }}$ Turma, AI no 754.913 AgR, Rel. Min. Gilmar Mesdes, DJe pub. 01/02/2008.
} 
Em seu segundo aspecto subjetivo, em que a Capacidade Contributiva se apresenta como critério de graduação dos tributos, é onde são encontradas as diferenças. Não que aqui o princípio se limite aos impostos. Aplica-se a todos os tributos também. Porém, sob uma perspectiva diferente. Nos impostos, o critério de graduação pela Capacidade Contributiva se dá pela personificação. Nas taxas pela referibilidade individual. Assim também nas contribuições de melhoria. Já os empréstimos compulsórios não possuem fato gerador próprio, geralmente utilizando-se daquele tipicamente aplicável aos impostos. Se assim for, a Capacidade Contributiva também se revelará pela personificação. Caso adote o fato gerador de taxa, o que raramente acontece, adotará a referibilidade individual. Por fim, nas contribuições parafiscais, a graduação se fará pela referibilidade de grupo.

A personificação, aplicável aos impostos pessoais e reais, uma vez que o patrimônio também personifica a riqueza do contribuinte, vai se revelar pela identificação, pelo legislador, de critérios quantitativos que não se relacionem com qualquer atividade estatal específica em relação à pessoa do contribuinte ou ao grupo que ele participa.

A referibilidade individual se manifesta por graduações nos elementos quantitativos do fato gerador do tributo, base de cálculo e alíquota, a partir da maior ou menor complexidade da atividade estatal relativa à pessoa do contribuinte.

Por fim, na referibilidade de grupo, os elementos quantitativos do fato gerador, base de cálculo e alíquota, devem se relacionar com o elemento finalístico, a partir da proporcionalidade entre a atividade estatal financiada pela contribuição e o grupo que os seus contribuintes participam.

\section{REFERÊECIAS:}

AMARO, Luciano. Direito Tributário Brasileiro. 16. ed. São Paulo: Saraiva, 2010.

ARISTÓTELES. Ética A Nicômaco. São Paulo: Martin Claret, 2000.

ÁVILA, Humberto. Sistema Constitucional Tributário. São Paulo: Saraiva, 2004.

BALEEIRO, Aliomar. Uma Introdução à Ciência das Finanças. 14.ed. Rio de Janeiro: Forense, 1987. 
BUCHANAN, James. The Limits of Liberty - Between Anarchy and Leviathan. Chicago: The University of Chicago Press, 1975.

CARRERA RAYA, Francisco José. Manual de Derecho Financiero. Vol. I. Madrid: Tecnos, 1993.

COÊLHO, Sacha Calmon Navarro. Comentários à Constituição de 1988 - Sistema Tributário. 3. ed. Rio de Janeiro: Forense, 1991.

CONTI, José Maurício. Princípios Tributários da Capacidade Contributiva e da Progressividade. São Paulo: Dialética, 1997.

COSTA, Regina Helena. Princípio da Capacidade Contributiva. São Paulo: Malheiros, 1993.

DANTAS, San Tiago. Programa de Direito Civil - Teoria Geral. Taquifragado por Victo Bourhis Jürgens. Revista e atualizada por Gustavo Tepedino, Antônio Carlos de Sá, Carlos Edison do Rêgo Monteiro Filho e Renan Miguel Saad. 3. ed. Rio de Janeiro: Forense, 2001.

DERZI, Misabel Abreu Machado. Notas de Atualização de BALEEIRO, Aliomar, Limitações Constitucionais ao Poder de Tributar. 7 ed. Rio de Janeiro: Forense, 1997.

GRECO, Marco Aurélio. Contribuições (uma figura "sui generis”). São Paulo: Dialética, 2000.

HERRERA MOLINA, Pedro Manuel. Capacidad Económica y Sistema Fiscal-Análisis del ordenamiento español a la luz del Derecho alemán. Barcelona: Marcial Pons, 1998.

JARACH, Dino. O Fato Imponível - Teoria Geral do Direito Tributário Substantivo. Traduzida por Dejalma de Campos, São Paulo: Revista dos Tribunais, 1989.

LEHNER, Moris. "Considerações Econômicas e Tributação conforme a Capacidade Contributiva. Sobre a possibilidade de Uma Interpretação Teleológica de Normas com Finalidades Arrecadatórias". In: SCHOUERI, Luiz Eduardo/ZILVETI, Fernando Aurélio (Coordenadores). Direito Tributário. Estudos em Homenagem a Brandão Machado. São Paulo: Dialética, 1998.

MACHADO, Hugo de Brito, Curso de Direito Tributário. 30. ed. São Paulo: Malheiros, 2009. 
OLIVEIRA, José Marcos Domingues. Direito Tributário - Capacidade Contributiva. 2. ed. Rio de Janeiro: Renovar, 1998.

PEREIRA, Caio Mário da Silva. Instituições de Direito Civil, Vol. I. 10. ed. Rio de Janeiro: Forense, 1987.

PEREZ DE AYALA, Jose Luis. Derecho Tributario I. Madrid: Editorial de Derecho Financiero, 1968.

RAWLS, John. Uma Teoria da Justiça. São Paulo: Martins Fontes, 1997.

RIBEIRO, Ricardo Lodi. “As Contribuições Parafiscais e a Validação Constitucional das Espécies Tributárias”. In: RDDT nº 174, 2010, p. 110-129.

Justiça, Interpretação e Elisão Tributária. Rio de Janeiro: Lumen Juris, 2003.

A Segurança Jurídica do Contribuinte - Legalidade, Não-surpresa e Proteção à Confiança Legítima. Rio de Janeiro: Lumen Juris, 2008.

ROSA JR., Luiz Emydio da. Manual de Direito Financeiro e Tributário. 17. ed. Rio de Janeiro: Renovar, 2003.

SEIXAS FILHO, Aurélio. Taxa - Doutrina, Prática e Jurisprudência. Rio de Janeiro: Forense, 1990.

SMITH, Adam. Riqueza das Nações. 3. ed. Lisboa: Calouste Gulberkian, 1999, Vol. II.

TIPKE, Klaus. Princípio da Igualdade e a Idéia de Sistema no Direito Tributário". In: BRANDÃO MACHADO (coord.). Estudos em Homenagem ao Prof. Ruy Barbosa Nogueira. São Paulo: Saraiva, 1984, p. 517-527.

- "Sobre a Unidade da Ordem Jurídica Tributária". In: SCHOUERI, Luiz

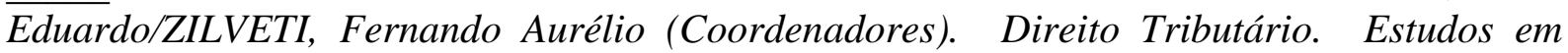
Homenagem a Brandão Machado. São Paulo: Dialética, 1998, p. 60-70. 
TORRES, Ricardo Lobo. Tratado de Direito Constitucional Financeiro e Tributário: Valores e Princípios Constitucionais. Vol. 2 Rio de Janeiro: Renovar, 2005

Tratado de Direito Constitucional Financeiro e Tributário, Vol. II - Valores e Princípios Constitucionais Tributários. Rio de Janeiro: Renovar, 2005; Vol. III. 2. ed. Rio de Janeiro: Renovar, 1999; Vol. IV - Os Tributos na Constituição. Rio de Janeiro: Renovar, 2007.

VALDÉS COSTA, Ramón. Instituciones de Derecho Tributario. Buenos Aires: Depalma, 1996.

VOGEL, Klaus. "Tributos Regulatórios e Garantia da Propriedade no Direito Constitucional da República Federal da Alemanha”. In: Brandão Machado (coord.). Estudos em Homenagem ao Prof. Ruy Barbosa Nogueira. São Paulo: Saraiva, 1984, p. 543-556.

ZILVETI, Fernando Aurélio. Princípios de Direito Tributário e a Capacidade Contributiva. São Paulo: Quartier Latin, 2004. 